mark an zwei Stellen eröffnet und vom dritten Rückenwirbel abwärts vollkommen und sorgfältig zerstört worden war, gebar das Thier doch zwei Tage darauf kurz vor seinem Tode : ein Junges.

In Betreff der vorn Rückenmark zum Uterus gehenden Nerven bestätigen meine Versuche die Ergebnisse früherer Forscher, 1) dass vom ganzen Rückenmarke aus Contractionen der Gebärmutter hervorgerufen werden können, besonders leicht vom Halstheile (bis zum aweiten Halswirbel) und Lendentheile ans; 2) dass noch nach Durchschneidung des Riickenmarkes unterhalb des letzten Halswirbels vom Halstheile des Rückenmarkes aus Contractionen der Gebärmutter (freilich bedeutend schwächere) erregt werden. Diese Contractionen sind nicht dem Finflusse des Halsmarkes anf dio Cireulation zuznschreiben, da sie auch dann noch eintreten, wenn an Stelle des natürlichen Blutumlaufes defibrinirtes Blut unter constantem Drucke durch den unteren Theil des Körpers strömt.

Die peristaltische oder antiperistaltische Richtung der Gebärmuttercontractionen scheint im Allgemeinen davon abzuhängen, an welcher Stelle der Reiz einwirkt, welcher die Contraction hervorruft.

In Bezug endlich auf die Meinungsverschiedenheit zwischen $K \ddot{o r}$ ner und Frankenhäuser (und Kehrer) über den Einfluss einer Unterbrechung der Circulation auf Hervorrufung von Contractionen der Gebärmutter, muss ich mich in Folge meiner Versuche mit künstlicher Circulation in dem unteren Körpertheile des Thieres entschieden auf Seite Körner's stellen und behaupten, dass Unterbrechung der arteriellen Blutzufuhr und Wiederzuströmen des Blutes den Uterus zu Contractionen anregt, dass indess ein Wechsel in der Höhe des Blutdruckes diesen Erfolg nicht hat.

\title{
Ein Fall von Geburtsstörung durch gleichzeitigen Eintritt von Zwillingen in das Becken.
}

Von

Dr. Reimann in Kiew.

Im Anschlusse an den Fall von Rintel im Februarheft 1869 der Monatsschrift für Geburtskunde theile ich einen Fall aus meiner Praxis mit:

Die 16jährige schwächliche Erstgebärende wurde am Ende der 
zweiten Geburtsperiode und nach Abfluss der Wässer von eklamptischen Anfüllen befallen. Der berbeigerufene Arzt legte die Zange an den vorliegenden Kopf und zog ihn leicht aus; die Schultern folgten indessen nicht, und bei der Untersuchung zeigte sich im Becken ein zweiter Kopf. Bei meiner Ankunft wollte der behan. delnde Arzt schon zur Abtrennung des geborenen Kopfes vom Rumpfe schreiten. Das halbgeborene Kind war todt, und die Herztöne des zweiten Kindes waren auch nicht mehr zu hören. Der schon geborene Kopf war mit dem Hinterhaupte nach oben und rechts gerichtet, der noch im Becken befindliche unter dem ersten liegende nach obeu und links; die Mutter war sehr angegriffen und erregt.

Eingedenk des von $\mathrm{H}_{0} \mathrm{hl}$ empfohlenen Verhaltens bei Missgeburten mit zwei Köpfen legte ich die Zange an den zweiten Kopf und entwickelte ihn leicht unter dem ersten Kopfe. Darauf gelang es leicht, den Rumpf erst des ersten, dann des zweiten Kindes zu entwickeln. Beide Kinder waren todt, vollkommen entwickelt, von mittlerer Grösse, männlichen Geschlechts; die Eihäute waren getrennt. Die Mutter starb nach einigen Tagen am Puerperalfieber.

Es muss dahingestellt bleiben, ob die Zangenextraction des ersten Kopfes Veranlassung zu dieser Geburtsstörung gab; wahrscheinlich ist es indessen nicht, da der von mir berichtete Fall der einzige bis jetzt beobachtete ist, in welchem der vorliegende Theil des ersten Kindes künstlich entwickelt worden war. Ueberhaupt sind die Ursachen dieser Geburtsstörung noch vollkommen unaufgeklärt, und kann man nur vermuthen, dass grosse Beckenmaasse nicht ohne Einfluss bleiben. Bemerkenswerth ist in meinem Falle noch die seltene Lage der beiden Kinder zu einander, während sie sich gewöhnlich mit den Vorderseiten berühren.

Die erwähnte Geburtsstörung gehört picht zu den seltenen, da in der Literatur sehon 31 Fälle bekannt sind. Freilich fehlen von einigen dieser Fälle die näheren Beschreibungen. In 22 Fällen befand sich das erste Kind in Unterendlage, bei 9 in Kopflage, das zweite Kind lag stets mit dem Kopfe vor. Die Geburt verlief fast in allen Fällen unglüeklich für das erste vorliegende Kind,' oft auch für das zweite, fuir die Mutter hatte die Geburt nur in meinem Falle einen unglïcklichen Ausgang.

Ausser den schon von $\mathrm{H}_{\mathrm{ohl}}$ und Rintel erwähnten Fälen finden sich beschrieben noch die Fälle von Thurston (Brit. med. Journ. 1867, 12. Oct.), Tell k a mp f (New-York med. Journ. 1867 May), Duhamel (Gaz. des hôpitaux 1853, 51), Braun (Allgem. Wien, med. Zeit. 1861, 1), Höd erich (Journ. d. Malgaigne 1845), Carrière (Journ. d. Malgaigne 1848), Calise (Gaz. méd. 1837), Eton (Lond, med. Gaz. 1846), Sidey (Edinb. med. Journ. Aug. 1855), Broers (Nederl. Tydschrift vor Heel. ete. 1856), Balfour. Ausserdem werden noch Fälle von Simpson, Leewins, de Lespinasse, r, achapelle erwähnt, aber nicht näher beschrieben. 
Ueber die in solchen Fällen einzuschlagende Behandlung kann, scheint es, nach den Erörterungen von $\mathrm{Hohl}, \mathrm{Braun}$ und $\mathrm{Ch}$ aillyHonoré kein Zweifel mehr obwalten.

\title{
Aus der geburtshülflichen Klinik zn Jena.
}

\author{
Ein Fall ron foetaler Rachitis mit Mikromelie. \\ Von
}

Dr. N. F. W in k 1 er.

(Mib Abbildungen Tafel II.)

Am 23. Mai 1870 wurde die Hülfe unserer Poliklinik inL obeda bei einer Frau L. verlangt, die seit 48 Stunden bereits kreisste. Angeblich fehlten bei dieser 5 para, die 36 Jahre alt, früher stets gesund war und stets leicht gesunde, jetzt kräftig entwickelte Kinder geboren hatte, $2-3$ Wochen bis zum normalen Ende der Gravidität. - Auch während dieser letzten Gravidität war die L., im Ganzen eine sehr kräftige muskulöse Frau mit mässigem Fettpolster, bis auf geringe Beschwerden in Folge schon zeitig eingetretener starker Ausdehnung des Leibes vollkommen gesund. Nur hatte sie während der Monate December, Jannar, Februar, wie die Mehrzahl hiesiger armer Leute, vorwiegend von Kartoffeln gelebt, ïber eine auffallende Schwäche und Mattigkeit zu klagen gehabt, die bald aufhörte, als es der Familie gelang, , von Ende Februar an wieder stärkere Fleischkost bei sich einzufuthren.

Wir fanden bei unserer Ankunft den Muttermund verstrichen, die Blase sprungfertig, den Uterus, der mit seinem Fundus den Rippenbogen, seitlich aber überall die verlängerte Axillarlinie erreichte, dauernd in so hoher Spannung, dass nicht einmal von einer ausgiebigen Palpation der Frucht die Rede sein konnte. Links ganz vorn wurde ein lebhaft ballotirender Körper gefühlt, aus dessen Härte, Rundung auf Kopf, und aus dessen Lage wahrscheinlich auf Querlage I, 1 (Kopf links, Rücken vorn) geschlossen wurde.

Da äussere Wendung für jetzt nicht möglich war, so wurde mit halber rechter Hand in die schlaffe Vagina eingegangen, somit ein sicherer Verschluss der letzteren hergestellt, dann am Ende einer 